\title{
The prediction of treatment failure of the continuous positive airways pressure
}

\author{
Slouka $\mathrm{D}^{1}$, Honnerova $\mathrm{M}^{2}$, Hrabe $\mathrm{V}^{1}$, Matas $\mathrm{A}^{3}$ \\ Ear, Nose and Throat Clinic, Charles University in Prague, Medical Faculty Pilsen, Pilsen, Czech Republic. \\ slouka.david@icloud.com
}

\begin{abstract}
Objective: The aim of study was to find predictive factors for treatment failure of the continuous positive airway pressure (CPAP).

Background: Sleep apnea syndrome (SAS) affects 4-8 \% of the general population. Despite good adherence, CPAP is ineffective in about $13 \%$ of patients. In those patients, a higher level of treatment by bilevel positive airway pressure (BiPAP) has to be used.

Methods: Totally, 983 patients with moderate to severe SAS (AHI $\geq 15$, apnea/hypopnea index) were treated with CPAP during 2005-2010 in a tertiary hospital. 506 patients fulfilled the inclusion criteria. In all patients, sleep monitoring was performed and $\mathrm{AHI}$, the presence of hyposaturation T90 (oxygen saturation less than $90 \%$ ) and ODI (oxygen distress index) were recorded and a comparison was made between CPAP-effective and CPAP-failure treatment groups.

Results: Of all the variables evaluated, only T90 significantly predicted the failure of CPAP treatment. A T90 value above $43.5 \%$ predicted CPAP failure in $94.5 \%$ of patients regardless of age.

Conclusions: The value of T90 enables the determination of patients who will not benefit from CPAP treatment and BiPAP should be used as a treatment of the first choice (Tab. 2, Fig. 1, Ref. 31). Text in PDF www.elis.sk. Key words: obstructive sleep apnea syndrome, conservative therapy of SAS, CPAP failure prediction.
\end{abstract}

Sleep-disordered breathing affects approximately $15 \%$ of the population (1). According to epidemiological studies, more than half are sleep apnea syndrome (SAS) whose diagnosis requires sleep monitoring, an ear-nose-throat examination (ENT) of the upper respiratory tract and a determination of treatment options $(2,3,4)$.

With increasing age, the proportion of the obstructive form of SAS (OSAS) increase, affecting up to $80 \%$ of patients, with central and mixed forms of SAS accounting for $10 \%$ each $(5,6)$.

Breathing disorders during sleep are accompanied by severe cardiovascular complications (7). Typically, no physiological decrease in systolic and diastolic blood pressure (non-dipper) occurs during night sleep due to the presence of apneic pauses. Sleep apnea syndrome is a risk factor for adverse cardiovascular events such as myocardial infarction, heart failure and stroke occurring 3 times more frequently in SAS patients $(8,9)$. In patients

${ }^{1}$ Ear, Nose and Throat Clinic, Charles University in Prague, Medical Faculty Pilsen, Pilsen, Czech Republic, ${ }^{2}$ Department of Pneumology, Charles University in Prague, Medical Faculty Pilsen, Pilsen, Czech Republic, and ${ }^{3}$ Department of Mathematics, Faculty of Applied Sciences, University of West Bohemia Pilsen, Pilsen, Czech Republic

Address for correspondence: D. Slouka, MD, Ear, Nose and Throat Clinic, Charles University Prague, Medical Faculty Pilsen, Edvarda Benese 13, CZ-305 99 Pilsen, Czech Republic.

Phone: +420.776893428

Acknowledgement: The authors thank all those who have helped in carrying out the research, mainly Assoc. Prof. Jaroslav Slipka, MD, the head of the Ear, Nose and Throat Clinic, Charles University in Prague, Faculty of Medicine Pilsen. The authors disclose no competing financial interest. with untreated SAS, atrial fibrillation is more common and reoccurs frequently even after successful cardioversion. Similarly, in diabetic patients glycaemic control could be difficult to achieve without treatment of SAS. Central nervous system symptoms, such as excessive daytime sleepiness (10) are the main clinical symptom severely limiting in everyday life activities leading to disability in some patients. In older patients with SAS, memory problems and depression are common and further worsen the quality of life $(11,12)$.

While in milder forms of SAS a surgical treatment is preferred, for patients with moderate to severe SAS, positive airway pressure (PAP) therapy is primarily indicated $(13,14)$. The first treatment choice is a single-level device with continuous positive pressure CPAP (15). Before treatment it is necessary to carefully choose the mask and determine the correct therapeutic pressure applied to prevent all adverse breathing events $(16,17)$. If CPAP fails, bi-level positive airway pressure (BiPAP) is the next step of treatment. Surgical treatment is an option depending on specific situations where the effect of PAP is limited by the obstruction of the upper airways $(16,17,18)$ or when conservative therapy for severe obstructive SAS fails $(19,20,21,22,23)$.

Approximately $13 \%$ of patients with good adherence to CPAP treatment experience treatment failure $(24,25)$. In these patients, CPAP prevents apneic pauses, but doesn't resolve the problem of hypoventilation. Residual AHI may be normal, but hyposaturation persists. Until now, only one study has dealt with this problem, however it did not evaluate clear factors predicting successful treatment with CPAP. 
Tab. 1. Study sample characteristics.

\begin{tabular}{|c|c|c|c|c|c|c|c|c|}
\hline Parameter & Minimum & Mean & Median & Maximum & $\mathrm{SD}$ & Q1 & Q3 & QD \\
\hline Apnoe-hypopnoe index & 15 & 52.37 & 51 & 120 & 21.2 & 36 & 68 & 32 \\
\hline Apnoe index & 0 & 35.75 & 31 & 114 & 24.1 & 17 & 55 & 38 \\
\hline Oxygen distress index & 13 & 53.36 & 53 & 120 & 21.5 & 35 & 70 & 36 \\
\hline T below 90\% $\mathrm{SaO} 2$ & 0 & 32.35 & 24 & 99 & 27.2 & 10 & 54 & 44 \\
\hline $\mathrm{SaO} 2$ & 64 & 88.58 & 90 & 96 & 4.3 & 87 & 91 & 4 \\
\hline Age & 33 & 58.91 & 60 & 89 & 10.2 & 53 & 65 & 12 \\
\hline
\end{tabular}

SD - standard deviation, Q1 - quartile 1,, Q3 - quartile 3, QD - quartile deviation

Tab. 2. CPAP treatment effect.

\begin{tabular}{|c|c|c|c|c|c|c|c|c|}
\hline \multirow[t]{2}{*}{ Parameter } & \multicolumn{4}{|c|}{ Successful treatment $(n=439)$} & \multicolumn{4}{|c|}{ Unsuccessful treatment $(n=67)$} \\
\hline & Mean & $\mathrm{SD}$ & Q1 & Q3 & Mean & SD & Q1 & Q3 \\
\hline Apnoe-hypopnoe index & 51.35 & 20.54 & 36 & 67 & 57.63 & 22.91 & 40 & 72 \\
\hline Apnoe index & 35.07 & 23.52 & 17 & 51.5 & 40.19 & 24.49 & 19 & 61 \\
\hline Oxygen distress index & 51.68 & 20.58 & 34 & 67 & 62.69 & 22.64 & 48 & 79 \\
\hline $\mathrm{T}$ below $90 \% \mathrm{SaO} 2$ & 28.47 & 25.15 & 9 & 45 & 56.06 & 27.21 & 32 & 75 \\
\hline $\mathrm{SaO} 2$ & 89.12 & 3.81 & 87 & 92 & 85.49 & 5.57 & 84 & 90 \\
\hline
\end{tabular}

SD - standard deviation, Q1 - quartile 1, Q3 - quartile 3,, QD - quartile deviation

The aim of our study was to compare selected characteristics of SAS in two groups of patients (groups with successful and unsuccessful treatment) to identify patients who will benefit from CPAP treatment, and those for whom a higher type of treatment such as BiPAP is primarily indicated $(26,27)$.

\section{Patients and methods}

\section{Patients}

Between 2005-2010, totally 983 patients were treated for SAS in the Faculty Hospital in the city of Pilsen, Czech Republic. The studied sample consisted of 506 consecutive patients who fulfilled the inclusion criteria: 367 males (73\%) and 139 females (27\%) with the mean age of $58.91 \pm 10.2$ year. A retrospective analysis of the patients' charts was carried out.

\section{Study sample characteristics}

Table 1 summarizes characteristics of the patients' sample.

\section{Ethics}

The Ethics Committee of the Faculty Hospital Pilsen granted approval of data analyses.

\section{Methods}

Inclusion criteria: an OSAS diagnosis determined by an ENT specialist and/or pneumologist, $\mathrm{AHI} \geq 15$, diagnostic and control evaluation performed with the same polygraphic monitoring systems (Miniscreen 8, Vitaloc, Stardust), the use of CPAP devices as the first choice of therapy, good adherence to the treatment by the patient.

Exclusion criteria: previous treatment of SAS including surgery, COPD, alcohol abuse.

The patient sample was divided into the two groups: successful treatment (group I) and unsuccessful treatment (group II). In all patients, the main polygraphic characteristics were recorded and the effectiveness of CPAP was evaluated. The differences in the observed parameters between the treatment group I and group II were analyzed. Additionally, we analyzed the influence of age on treatment success.

The following variables were recorded:

- The AHI (apnea-hypopnea index) was defined as the total number of apnea and hypopnea during one hour.

- The AI (apnea index) was defined as the total number of apnea during one hour.

- The ODI (oxygen distress index) was defined as the average desaturation per hour of sleep.

- Average saturation was defined as the mean $\mathrm{SaO}_{2}$ during sleep.

- T90 was defined by the percentage of sleep time below $90 \% \mathrm{SaO}_{2}$.

- Mild SAS was defined as AHI 5-14.9

- Moderate SAS was defined as AHI 15-29.9

- Severe SAS was defined as AHI 30 and more.

- The effect of CPAP was assessed after 3 months of treatment.

- Treatment failure was defined as: A) AHI $>10$ and lower than $75 \%$ decrease of baseline AHI value; B) AHI $<10$ but persisting hyposaturation, $\mathrm{T} 90 \geq 10 \%$ and $\mathrm{ODI} \geq 10$.

\section{Statistical methods}

For the statistical evaluation, we used the standard methods for testing hypotheses concerning the agreement of variance and mean values with a significance level of 0.05 and 0.01 . The most appropriate method was the discriminating method "minimum distance to type value" of the given class. The threshold value for the parameter T90 was determined empirically to provide the best possible discriminating features (28).

\section{Results}

\section{CPAP treatment effect}

Table 2 summaries characteristics of patients with successful and unsuccessful treatment. 


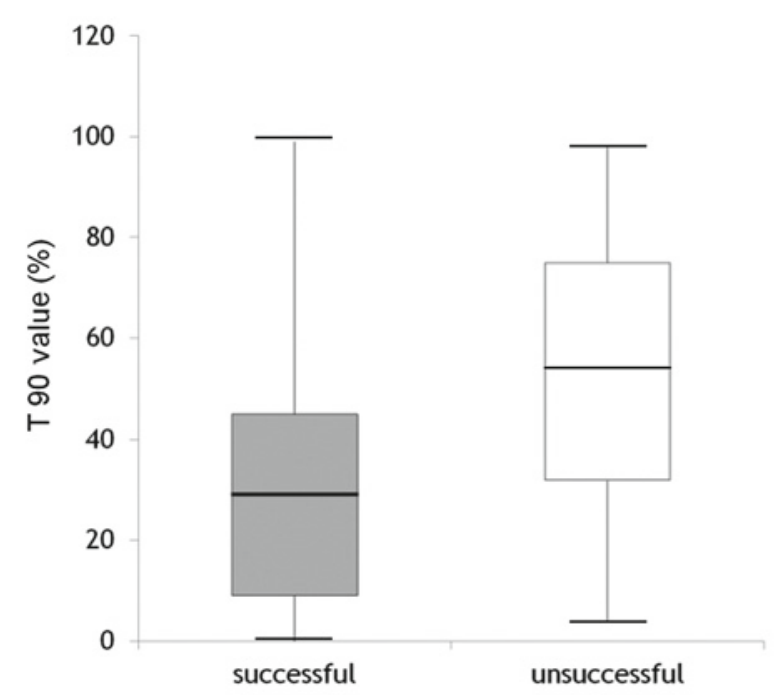

Fig. 1. The examination of T90 value.

When examining the values of AHI, AI and ODI parameters a direct correlation and relation to the successfulness of CPAP treatment cannot be established.

When examining the variance of $\mathrm{SaO}_{2}$ and the mean value of $\mathrm{SaO}_{2}$, the parameter was mathematically possible as a discrepancy criterion between both groups, nonetheless not advantageous for practical use for a low variance of values.

Through T90 analysis (Fig. 1) we found that the mean values did not match, and in these two groups, they differed significantly. T90 was a very good indicator in cases of CPAP failure.

Based on the threshold value of 43.5 for the T90 parameter, successful treatment was predicted in $94.5 \%$ of cases.

When examining the age differences, the mean values did not statistically differ between both groups. Thus, CPAP treatment failure did not seem to be influenced by age and was not more likely in older patients.

\section{Discussion}

The number of patients with SAS is high and as medical care continues to improve, the number of patients diagnosed and treated for SAS will increase. The medical and socio-economic impact on untreated or poorly treated patients is so serious that it warrants proper diagnosis and treatment.

Sleep apnea syndrome is a disabling condition in all ages, as there is more vulnerability to adverse cardiovascular events and disability. Considering that at higher ages there is a special emphasis put on minimally invasive and conservative procedures, the possibility of a simple prediction of success is essential. However, only a few authors evaluated factors contributing to treatment failure.

Repeating critical information improves the patient's adherence to treatment and contributes to better problem solving during SAS treatment. Particularly in elderly patients, communication plays a critical role $(29,30)$. It shows the interdisciplinary and complex nature of SAS. In our centre, patients profit from stepwise information consisting of the educational film, interview with a nurse and finally, by a doctor.

In this study, $13 \%$ of patients did not achieve satisfactory results after 3 months of CPAP treatment and patients had to switch to the BiPAP type of ventilation. Comparable results were published by Schäfer in a smaller sample of 146 patients (31). Unfortunately, this topic is not dealt with in other literature. We confirmed the results on a larger and unselected (representative) sample of patients at the University hospital.

We are aware that a retrospective single centre study may limit a generalization of our results. However, the large number of patients and demographic distribution support our findings (2). At the time, a prospective multi-centre study is being carried out to verify our results.

For parameters AHI, AI, ODI, no relationship to the treatment effect was found. Despite the fact that $\mathrm{SaO} 2$ showed a direct mathematical relationship to treatment failure, its utility in clinical practice is limited. The surprising fact was that CPAP treatment failure did not show a relationship to the age of the patient and thus, older patients have the same chance of successful CPAP treatment as younger patients.

The only clinically useful variable is T90, for which we computed a cut off value of 43.5. Patients with T90 of 43.5 or less had a $94.3 \%$ probability of successful CPAP therapy. This marker is commonly used in classical everyday work in centers of sleep medicine and offers us a cheap and practical possibility to choose the right type of treatment for each patient in the first step of therapy.

\section{References}

1. Mannarino MR, Di Filippo F, Pirro M. Obstructive sleep apnea syndrome. Eur J Intern Med 2012; 23 (7): 586-593.

2. Vozoris NT. Sleep apnea-plus: prevalence, risk factors, and association with cardiovascular diseases using United States population-level data. Sleep Med 2012; 13 (6): 637-644.

3. Sonka K, Nevsimalova S. 60 years of sleep medicine at the Department of Neurology, First Faculty of Medicine, Charles University in Prague and General University Hospital in Prague. Prague Med Rep 2011; 112 (3): 236-243.

4. Sonka K, Nevsimalova S, Trefny M, Ramaisl R, Klozar J, Hoskovec P. The sleep apnea syndrome. Basic diagnostic and therapeutic possibilities. Cas Lek Cesk 1993; 132 (6): 164-168.

5. Selim BJ, Junna MR, Morgenthaler TI. Therapy for sleep hypoventilation and central apnea syndromes. Curr Treat Options Neurol 2012; 14 (5): 427-437.

6. Marcus CL, Brooks LJ, Draper KA et al. Diagnosis and management of childhood obstructive sleep apnea syndrome. Pediatrics 2012; 130 (3): e 714-755.

7. Monahan K, Redline S. Role of obstructive sleep apnea in cardiovascular disease. Curr Opin Cardiol 2011; 26 (6): 541-547.

8. Kasai T. Sleep apnea and heart failure. J Cardiol 2012; 60 (2): 78-85.

9. Barbe F, Duran-Cantolla J, Sanchez-de-la-Torre M et al. Effect of continuous positive airway pressure on the incidence of hypertension and 
cardiovascular events in nonsleepy patients with obstructive sleep apnea: a randomized controlled trial. JAMA 2012; 307 (20): 2161-2168.

10. Dostalova S, Susta M, Vorlova T, Sonka K. Sleepiness in patients with obstructive sleep apnoea - daytime course and impact of nocturnal respiratory events. Neuro Endocrinol Lett 2012; 33 (7): 684-688.

11. Onen F, Onen H. Obstructive sleep apnea and cognitive impairment in the elderly. Psychol Neuropsychiatr Vieil 2010; 8 (3): 163-169.

12. Bruin PF, Bagnato Mda C. Cognitive impairment in obstructive sleep apnea syndrome. J Bras Pneumol 2010; 36 (Suppl 2): 32-37.

13. Butner KL, Hargens TA, Kaleth AS, Miller LE, Zedalis D, Herbert WG. Association of Obstructive Sleep Apnea Severity with Exercise Capacity and Health-related Quality of Life N Am J Med Sci 2013; 5 (6): 362-366.

14. Epstein LJ, Kristo D, Strollo Jr PJ et al. Clinical guideline for the evaluation, management and long term care of obstructive sleep apnea in adults. J Clin Sleep Med 2009; 5 (3): 263-276.

15. Chowdhury O, Wedderburn CJ, Duffy D, Greenough A. CPAP review. Eur J Pediatr 2012; 171 (10): 1441-1448.

16. Williams B, Boyle M, Robertson N, Giddings C. When Pressure is Positive: A Literature Review of the Prehospital Use of Continuous Positive Airway Pressure. Prehosp Disaster Med 2013; 28 (1): 52-60.

17. Leidag M, Hader C, Keller T, Meyer Y, Rasche K. Mask leakage in continuous positive airway pressure and C-Flex. J Physiol Pharmacol 2008; 59 (Suppl 6): 401-406.

18. Maurer JT. Surgical treatment of obstructive sleep apnea: standard and emerging techniques. Curr Opin Pulm Med 2010; 16 (6): 552-558.

19. Ephros HD, Madani M, Yalamanchili SC. Surgical treatment of snoring \&amp; obstructive sleep apnoea. Indian J Med Res 2010; 131: 267-276.

20. Cheng PW, Fang KM, Su HW, Huang TW. Improved objective outcomes and quality of life after adenotonsillectomy with inferior turbinate reduction in pediatric obstructive sleep apnea with inferior turbinate hypertrophy. Laryngoscope 2012; 122 (12): 2850-2854.

21. Jalbert F, Lacassagne L, Bessard J, Dekeister C, Paoli JR, Tiberge M. Oral appliances or maxillomandibular advancement osteotomy for severe obstructive sleep apnoea in patients refusing CPAP. Rev Stomatol Chir Maxillofac 2012; 113 (1): 19-26.
22. Browaldh N, Markström A, Friberg D. Elective tracheostomy is an alternative treatment in patients with severe obstructive sleep apnoea syndrome and CPAP failure. Acta Otolaryngol 2009; 129 (10): 1121-1126.

23. Foltán R, Sonka K. Genioglossal advancement in the surgical treatment of obstructive sleep apnea syndrome in adults. Sb Lek 2000; 101 (4): 393-398.

24. Mulgrew AT, Lawati NA, Ayas NT, Fox N, Hamilton P, Cortes L. Residual sleep apnea on polysomnography after 3 months of CPAP therapy: clinical implications, predictors and patterns. Sleep Med 2010; 11 (2): 119-125.

25. Sopkova Z, Dorkova Z, Tkacova R. Predictors of compliance with continuous positive airway pressure treatment in patients with obstructive sleep apnea and metabolic syndrome. Wien Klin Wochenschr. 2009; 121 (11-12): 398-404.

26. Dohi T, Kasai T, Narui K, Ishiwata S, Ohno M, Yamaguchi T. Bilevel positive airway pressure ventilation for treating heart failure with central sleep apnea that is unresponsive to continuous positive airway pressure. Circ J 2008; 72 (7): 1100-1105.

27. Piper AJ, Wang D, Yee BJ, Barnes DJ, Grunstein RR. Randomised trial of CPAP vs bilevel support in the treatment of obesity hypoventilation syndrome without severe nocturnal desaturation. Thorax 2008; 63 (5): 395-401.

28. Hatle J, Likes J. Zaklady poctu pravdepodobnosti a matematickestatistiky. Praha: SNTL, 1974: 320 - 328

29. La Piana GE, Scartabellati A, Chiesa L, Ronchi L, Raimondi P. Long-term adherence to CPAP treatment in patients with obstructive sleep apnea: importance of educational program. Patient Prefer Adherence 2011; 5: $555-562$.

30. Morales CR, Hurley S, Wick LC, Staley B, Pack FM. In-home, self-assembled sleep studies are useful in diagnosing sleep apnea in the elderly. Sleep 2012; 35 (11): 1491-1501.

31. Schäfer H, Ewig S, Hasper E, Lüderitz B. Failure of CPAP therapy in obstructive sleep apnoea syndrome: predictive factors and treatment with bilevel-positive airway pressure. Respir Med 1998; 92 (2): 208-215.

Received February 20, 2014. Accepted May 31, 2014. 